\title{
Space and Students Classroom Behavior in Elementary School
}

\author{
D. Tandyonomanu \\ Universitas Negeri Surabaya \\ Surabaya, Indonesia \\ danangtandyonomanu@unesa.ac.id
}

\begin{abstract}
This research aim to analyze theoretically the impact of distance to student's nonverbal behavior in learning situations. In recent years, it is believed that the method of collaborative learning is the best choice for learning and teaching process. This raises the different seating arrangement in many classrooms. This study used ethnographic methods of communication to observe these velar classrooms with different eating arrangements. Expectancy Violation Theory (EVT) used to underpin the understanding of differences in student behavior as a reaction to seating arrangement. The distance between teacher and student who are physically and psychologically closed would show a more favorable student behavior, but not the otherwise.
\end{abstract}

Keywords-space; students behavior; classroom seating arrangements;

\section{INTRODUCTION}

Learning activity is a transfer of knowledge activity. In this activity, not only the ability of teachers in subject matter and pedagogy should be mastered, but also deal with how doing it effectively. To perform these activities, the ability of communication also becomes a necessity. Communication skills are the ability to utilize verbal and nonverbal aspects appropriately.

Verbal communication not only with regard to the selection of the right words to avoid misconceptions, but also relates to made simplified sentences, clear and understandable, also the use of words that motivate students. Likewise, the nonverbal aspects. Each teacher nonverbal behavior will also affect the learning climate. Students can be enthusiastic and motivated to continue to engage in any learning activity. Verbal and nonverbal behavior of the teacher will affect the participation of student learning. Teachers who used short sentences and do not able to paraphrase a sentence that provides the best explanation of the subject, and also show unfavorable nonverbal behavior would not be responded enthusiasm. [1]

Teachers perceived 'close' by the students would be more acceptable than the teachers who do not 'close'. This is known as teacher immediacy. Mehrabian (1971) was the first introduced the concept of teacher immediacy. He defined immediacy as behaviors which "enhance closeness to and nonverbal interaction with another". [2]
Since introducing by Mehrabian some research conducted related to the immediacy and student learning. Some prior research result are: (a) Immediacy will attract students' attention, and in turn can improve the cognitive learning [3]; (b) Immediacy can increase student motivation, which in turn can improve learning [4]; (c) Immediacy increase the effect of teachers and content, which may improve cognitive learning [5] ;(d) Teacher immediacy can enhance positive emotional response, which then can improve learning [6]. Briefly, teacher immediacy improves process and outcome of learning.

Immediacy does not only have an effect on students, but also for teachers. Students who are motivated and attracted to learning will make teachers more motivated in sharing information. This is called student immediacy. Students who perceived close by the teacher will increase the motivation of teachers to teach. So, immediacy is also a positive impact on improving the performance of teachers [7].

The concept of teacher immediacy associated with the teacher's verbal and nonverbal behavior. If such behavior perceived by students as supportive act, then the teacher considered has psychological closeness by the students. According to Richmond, immediacy is a perception of physical or psychological closeness [8].

Immediacy can be verbal and nonverbal symbols. Verbal immediacy can be demonstrated by using the student's name to call, inclusive language (we, us), using humor, use of the phrase that increase participation. And the nonverbal aspect may include appearance, gesture and movement, facial behavior, eye behavior, vocal behavior, space, touch and the environment.

In a classroom setting, there was a shift trend in learning activities. Curriculum-2013 has a different approach, which is a collaborative learning. This approach provides opportunities for students to learn in groups to accomplish tasks. Although this approach gives a wider opportunity for student to learn collaboratively, but teacher as a primary role still remains. Teacher developed a lesson plan that determined what and how students should behave in the classroom. The teacher determines which learning activity will be conducted, including when the students have to collaborate or work alone, when allowed to ask questions or express opinions. In every students' learning activity, teacher has a different role. When teacher act as a tutor, student should listen, when 
student work in group, the teacher acts as facilitator. In this case, the presence of teachers remains a key role in learning process.

In the collaborative learning required student seats that face each other. There are two models of seating arrangement as the implications for collaborative learning: the conventional model and the cluster model. This study aims to reveal how the nonverbal aspects of teachers, namely space as the implications of different seating arrangements will elicit a response in the form of different behaviors. The theoretical analysis is performed to find the explanations of student behavior.

\section{METHOD}

This study used ethnography methods of communication, the study of the speech community, but not in the mean of verbal communication, but rather focuses on nonverbal communication. Observation as the primary method to get the data. For data collection needs, learning activities recorded in the form of video. With video makes it possible to watch again to get the accurate data and used it for further discussion. This study was conducted in nine elementary schools, grade 2 until 5. Researcher act as a passive participant, involved in class passively as an observer. Most schools were accustomed to the presence of observers from outside their school, so they are not disturbed by the presence of others in the class. Classes which are unfamiliar with the observer will be distracted, but this happens at the initial stage only. Once the learning activities start, students are more focused on teaching and learning activities. The object of observation was the teacher in terms of relative position (distance) to students in the classroom, and student responses in the form of the behavior exhibited. The theoretical analysis is used to provide an explanation about the relation of the distance between teacher-student and the reaction of the students.

\section{DATA FINDING}

In this study, there are two types of classroom seating arrangements: the conventional model and the cluster model. First, conventional model takes the form of a seat arrangement of the direct instruction model. Direct instruction emphasizes the teacher as the main actors are active while the students passively listening. Discussion and questions remain exist, but it's happening in the control of the teacher. Teachers who give students a turn to ask questions, to answer or silently.

The conventional model is a model of student seating arrangement that composed of four columns by five/six rows back (see figure 1). All students facing the blackboard. Facing to the location where the teacher does most of the teaching activities. For the purpose of collaborative learning, some students turned their chair, so they can face with each other into groups. No changes in the composition of the student seats, but only rotate the seat. Teachers in collaborative learning act as a facilitator, which is involved in each group to provide guidance to improve student achievement.
Area movement of teacher in a conventional model is through the aisle that separates rows of seats. From the front area, teachers who want to involve in the group as facilitator must be walked down the aisle that separate students' seat. For example, if a teacher want to a group on the left-rear of the class, the teacher must be walked through the left aisle and go to the farthest area in the rear of the class. And, if the teacher wants to involve into group in the right-rear, side, then teachers must walk-through the front of the class, then walk to the right-rear.

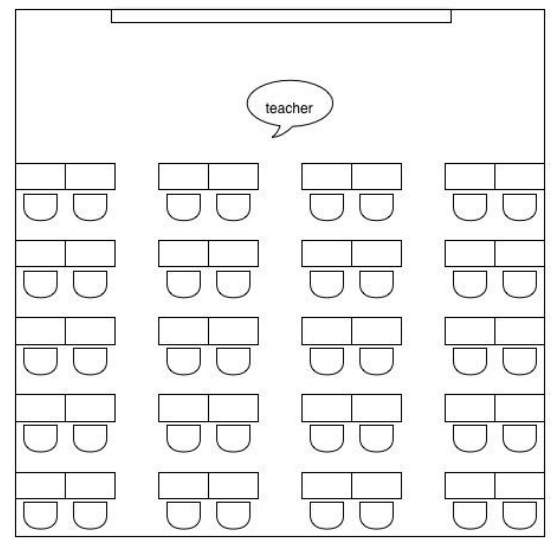

Fig. 1. Conventional Model of Seating Arrangement

Data from conventional model shows that students perform unfavorable behavior when they have distance that far from the teacher. Distance could mean two things, physically and psychologically. Physical distance is the distance that has length of space between teacher and students. For example: teacher stand in front of the class has close physically distant (to students sitting in the front row). Conversely, the distance of student sat in rear corner of the class is far.

Psychological distance is the students' perception of the presence of the teacher. A teacher who stands in left-rear aisle physically are close to student seated at the right-rear aisle. But, because teachers could not reach student seated on the opposite side of class straight away, and should walk around through in front of the class, then students' perception would consider the teacher are far.

Second, cluster model. This model is to arrange the student's seat into groups that always face each other (see figure 2). Every cluster consist of 5-6 students. Cluster model design for collaborative learning. If teacher need to give a classical information or explanation, students will turn their chair to face the teacher. The teacher position could be in front the class, near the whiteboard, or in the middle of class. The teacher could easily move from in front the class to the middle. Using space in the middle of the class, teacher could maintain to the same distant among students. These distances would perceive as near in both physical and psychological. 
The result of observation shows that the cluster model to bring out more conducive behavior than conventional models. Conducive because students would more focus and increase the participation in collaborative learning. Otherwise in conventional model. If teacher were on the left side, students in the right side tend to behave negatively. Students started to ignore and passive in collaborative work, sometimes they started to bother other member of groups, made some noises. This unfavorable behavior would gradually become favorable if teacher starts to approach and give support to the student or groups. The teacher moved to the other side of the class would make the students' behavior positive, otherwise, students which just left behind would start became negative behavior.

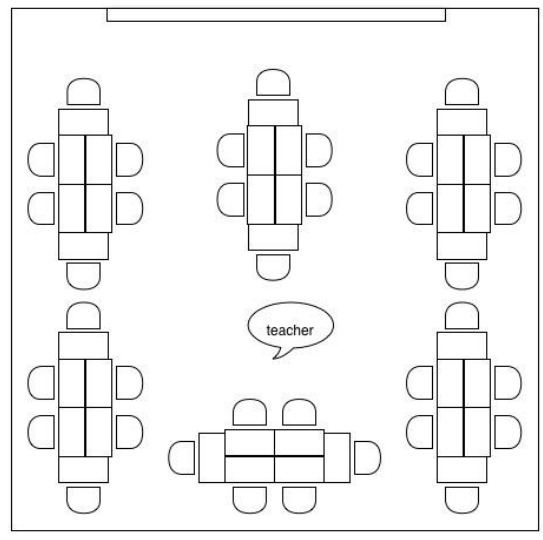

Fig. 2. Cluster Model of Seating Arrangement

The different behavior of the two models was related to psychological distance between teacher and students (see Table I). In the conventional model, teacher movement to reduce distant blocked with the classroom seating arrangement. Different physically distant would show different behavior. Favorable behavior if near, but unfavorable if far. But this condition was different from cluster model. Relatively, distance between teacher and students were near. So, students show the same behavior, which is favorable to learning.

TABLE I. TEACHER POSITION AND STUDENTS BEHAVIOR IN CONVENTIONAL AND CLUSTER MODEL

\begin{tabular}{|l||l|l|}
\hline & Conventional Model & Cluster Model \\
\hline \hline $\begin{array}{l}\text { Teacher } \\
\text { movement }\end{array}$ & Aisle between rows & $\begin{array}{l}\text { Space between seat } \\
\text { cluster }\end{array}$ \\
\hline $\begin{array}{l}\text { Physical distance } \\
\text { (meter) }\end{array}$ & $1-12$ meter & $1-4$ meter \\
\hline $\begin{array}{l}\text { Psychological } \\
\text { distance }\end{array}$ & $\begin{array}{l}\text { Close (1-4 meter); } \\
\text { Far (8-12 meter) }\end{array}$ & Close \\
\hline $\begin{array}{l}\text { Students' } \\
\text { behavior }\end{array}$ & $\begin{array}{c}\text { Close: focus and } \\
\text { increase } \\
\text { participation; } \\
\text { Far: ignorance and } \\
\text { passively in } \\
\text { collaborative work }\end{array}$ & $\begin{array}{l}\text { Focus and increase } \\
\text { participation }\end{array}$ \\
& \multicolumn{2}{|c}{} \\
\hline
\end{tabular}

Walk around to reach the other side of the class would take time. An effort to help the students' needs became a problem. In the conventional model, delayed to serve students need would be perceived as psychologically far. In turn, this would bring out unfavorable behavior.

\section{DISCUSSION}

In the context of this study, immediacy is more emphasis on the distance between teachers and students. And seating arrangements in the classroom affect the teachers' efforts to position themselves among the students.

Judee Burgoon provides a theoretical framework that can provide an explanation of how distance can bring different behaviors. Borgoon analyze the expectancy violation theory (EVT). According to Burgoon, each individual has a personal space, which is defined as "the invisible, variable volume of space surrounding an individual that defines that individual's preferred distance from others [9]". Houser is using EVT to analyze the learning activities. That expectation towards the trainer will affect cognitive learning and increase motivation [10].

The idea of personal space preceded by Edward Hall with his thoughts about proxemics, as the study of people use of space as a special elaboration of culture [11]. According to hall, every individual has proxemics zone: intimate distance; personal distance; social distance; and public distance. This proxemics zone differs in every culture. For the American who appreciate privacy, the physical distance desirable for people he knew would be different from the Arabs who have a different culture. Hall suggested to be effective, we have to adjust the behavior of nonverbal communication rules according to other desires. In this case the teacher must adapt nonverbal behavior (distance) to establish effective communication with students.

The core concept of the EVT is expected. Everyone has expectations of what others are doing. This expectation is influenced by the context of the communication, the type of relationship, and characteristics of other people. The context of the communication relating to the setting of ongoing communication. In a situation of learning the relationship between teachers - students if it is in a different context, such as recreation. Nonverbal behavior of teachers - students currently in the class would be different if they are in a park.

Type of relationship with regard to the similarity, familiarity, liking and relative status. We allow people who are known to have a shorter distance, compared with a stranger. The teacher is a status that allows a student as someone close. So that students will receive the closeness of teachers, especially for purposes of understanding the learning materials. 
Last, the expectations with regard to the characteristics of others. People who tend to be rough were undesirable to close. Likewise, the characteristics of the killer teacher, funny teacher, a good teacher will determine their closeness to us.

The next key concepts of EVT are a violation, which refers to "the perceived positive or negative value assigned to a breach of expectation, Regardless of who the Violator is"[12]. Not all the distance that we expect will be fulfilled, then there is a violation of expectations. If this happens, we begin to evaluate whether this act will be accepted or not, depending on who makes a violation. The next decision will determine that the communications will be passed or stopped. Decisions are taken based on the evaluation that we did during the communication process takes place. If the evaluation results indicate a positive result then communication will continue, if not the focus of the communication participant will change.

EVT can be used to analyze the behavior of communication in relation to the distance. In elementary school, the teacher can be interpreted to have psychological closeness to the students. Even teachers can act as parents for students to be in school. This closeness condition will dwindle along with the development of age. This suggests that teachers occupy a position as part of the circle of personal zone.

In a learning situation, the teacher is expected to be a person who can show caring attitude, pay attention, warm, and helpful. This expectancy will be achieved if teachers were perceived within personal distance. Thus, teachers should take a position in personal distance to be functioning as expected of students. If so, students will exhibit behaviors that are favorable, such as paying attention, not to interfere with his acting, and focus on the learning process.

However, these conditions can be implemented as expected. Ideally, teachers always perceived positively by managing the 'closing'. In the cluster models, the teacher attempts to regulate the closeness can be carried out more freely. Teachers can move, closer to each student. However, the ease not found in conventional models. To reach the other side of the class are separated by distance and also takes time to be able to serve all. Longer distances will cause the students' perception of teacher to be negative. As a result, students show unfavorable behavior.

\section{CONCLUSION}

Classroom seating arrangements have an impact on student behavior. Conventional models provide difficulties for teachers to reach students personally, while the cluster models are relatively easy to maintain physical and psychological distance that is perceived positively by the students. And this will be a positive perception of the students responded by showing favorable behavior.

\section{REFERENCES}

[1] Danang Tandyonomanu, "Komunikasi Pembelajaran Mahasiswa Calon Guru Pada Program Studi Pendidikan Guru Sekolah Dasar Universitas Negeri Surabaya”, Dissertation. Bandung: Padjadjaran University, 2012, unpublished

[2] Mehrabian, A. Silent Message. Belmont, CA: Wadsworth. 1971.

[3] J. Comstrock, Rowell, E., \& Bowers, J. "Food for Thought: Teacher nonverbal Immediacy, Student learning, and Curvilinearity". Communication Education. Vol 44. 1995. Pp 251-266.

[4] D.M. Christophel. "The Relationship among teacher immediacy Behaviors, Student Motivation and Learning". Communication Education. Vol. 39. 1990. pp.323-340

[5] J.I. Rodriguez, Plax, T.G., \& Kearney, P. "Clarifying the Relationship Between Teacher Nonverbal Immediacy and Student Cognitive Learning: Affective Learning as the Central Causal Mediator". Communication Education. Vol 45. 1996. pp. 293-305

[6] T.P. Mottet, \&S.A. Bebe. "Relationship Between Teacher Nonverbal Immediacy, Student Emotional Response, and Percieved Student Learning". Paper presented at the annual meeting of the National Communication Association. Atlanta. November 2001

[7] Doreen K. Baringer and James C. McCroskey, "Immediacy in Calssroom: Student Immediacy," in Communication Education, vol. 49, No. 2 April 2000, pp. 178-186

[8] V.P. Richmond."Teacher nonverbal immediacy: Uses and outcomes". in J.L. Chesebro and J.C. McCroskey (eds.) Communicaton for teacher. Boston: Allyn and Bacon, 2002, pp. 65-80

[9] Em Griffin, "The first look at communication theory. 8th ed., New York: McGraww-Hill, 2012, pp. 85

[10] Marian L. Houser,"Expectancy Violations of Instructor Communication as Predictors of Motivation and Learning: A Comparison of Traditional and Nontraditional Students". Communication Quarterly. Vol. 54, No. 3, August 2006, pp. 331-349

[11] Edward T. Hall, "The hiddern dimension", Garden City, NY Doubleday, 1966, pp. 1

[12] Em Griffin, "The first look at communication theory. $8^{\text {th }}$ ed., New York: McGraww-Hill, 2012, pp. 90 